\title{
Study thermo-mechanical properties of polyester composite reinforced by ceramic particles, SiC
}

\author{
Falak O. Abas ${ }^{1,}$, Raghad Usama Abass ${ }^{2}$ \\ ${ }^{1}$ Applied science department, environmental research center, university of technology, Iraq. \\ ${ }^{2}$ Applied science department, Applied Science Department, Iraq, Baghdad.
}

\begin{abstract}
Development of the Polymer Composites with natural fibers and fillers as a sustainable alternative material for some engineering applications, particularly in aerospace applications and automobile applications are being investigated. Lightweight and biodegradability and low cost Polyester composites are synthesised with an addition of Silicon carbide $(\mathrm{SiC})$ particles by varying weight percentage $(0,3,6,10,13$, and 16 wt. \%) respectively by using hand- layup technique followed by cold moulding. The prepared specimens were cut according to ASTM standard to determine hardness, impact strength, bending distortion and thermal conductivity properties. Afterward, the thermal and mechanical properties of all the unfilled and particulate filled composites are also evaluated for structural applications, i.e., hardness, impact strength, bending distortion, are determined with the change in filler content to notice the behaviour of composite material subjected to loading in addition to thermal conductivity property. Thermo-mechanical properties of the material are measured with the help of testing machines above according to their ASTM. It is found that the strength properties are greatly influenced by addition of this ceramic filler. Also shows that the thermal and mechanical properties of SiC-filled polyester composites are better than unfilled base composites
\end{abstract}

\section{Introduction}

Polyester composites form important class of engineering materials and are commonly used in mechanical components. Because of their high strength-to-weight and stiffness-to-weight ratios, they are extensively used for a wide variety of structural applications as in aerospace, automotive, gear pumps handling industrial fluids, cams, power plants, bushes, bearing cages and chemical industries. The popularity of polymers is due to their high specific strength and stiffness however polymer composites have poor erosion resistance as compared with metal matrix composites [1-5].The physical and mechanical characteristics of composites can be modified by adding a filler phase to the matrix body during the composite preparation. The

*Corresponding author: falak_usama@yahoo.com 
incorporation of filler in composite is to improve its mechanical properties and to reduce its cost [6-10]. Therefore, the use of inorganic filler in the composite is gaining popularity in the composite world there are many investigations on filler in the polymer [11,12] and in the fibre reinforced composite $[13,14]$. Ceramic rich industrial by-product, which consists of oxides of metals, can also be potential filler [15]. Chemosphere is the one of the industrial waste produced during burning of coal in thermal power plant [16]. And several instances of investigation of mechanical properties of the chemosphere filled composites [17-20].

In the industry, the addition of filler materials to a polymer is a common application that improves not only stiffness, toughness, hardness, heat distortion temperature, and mould shrinkage, but also reduces the processing cost significantly. In fact, more than $50 \%$ of all produced composites systems are in one way or another filled with inorganic fillers to achieve the desired properties [21]. The addition of filler consisting of a combination of Silicon and carbon black powders decrease the negligible amount residual free Silicon but increased the amount of internal reaction bonded $\mathrm{SiC}$ and filler reduced the flexural strength indicating damage to the fiber but it drastically improved the wear resistance characteristics of the composites [22]. Silicon carbide $(\mathrm{SiC})$ is one such ceramic material that has great potential for overcoming the current inadequacies of abrasive products due to its inherent characteristic of being chemically inert and consequently resistant to improve mechanical and wear resistance material. It has an excellent abrasive nature and has been produced for grinding wheels and other for more than hundred years. Now-a-days the material has been developed into a high quality technical grade ceramic with very good mechanical properties. It is used in abrasives, ceramics, refractory, and other high-performance applications. The material can also be made an electrical conductor and has applications in resistance heating, flame igniters, and electronic components. Silicon carbide is composed of tetrahedral carbon and silicon atoms with strong bonds in the crystal lattice. This produces a very hard and strong material. It is not attacked by any acids, alkalis, or molten salts up to $800{ }^{\circ} \mathrm{C}$. The high thermal conductivity coupled with low thermal expansion and high strength gives this material exceptional thermal shock resistant qualities. Also have low density of about $3.1 \mathrm{~g} / \mathrm{cm} 3$, high elastic modulus, high strength, high hardness, excellent thermal shock resistance, and superior chemical inertness [23, 24-26]. It may develop a new class of based polymer composite filled with $\mathrm{SiC}$ particulate and study the effect of various operational variables, material parameters and their interactive influences on erosive wear behaviour of these composites to obtain the desired material characteristics for a particular application, it is important to know how the changes in performance characteristics of the composite vary with filler content under given loading conditions. Hard particulate fillers consisting of ceramic or metal particles are being used these days to dramatically improve the wear resistance and improve their mechanical properties, even up to three orders of magnitude [23]. Fillers affect the strength of the composite according to their packing characteristics, size and interfacial bonding [24].

The mechanical properties of a composite determine the range of usefulness of a material and establish the service life that can be expected. Most structural materials are anisotropic, which means that their mechanical properties vary with orientation. The variation in the properties can be due to the change in the microstructure of fiber/filler and matrix reinforcement. The materials can be subjected to many different loading scenarios, and the composite performance is dependent on the loading conditions. The common properties are considered to determine the loading constraints on the durability and service life effect tensile strength, flexural strength, hardness, interlaminar shear strength (ILSS), and impact strength [25], Ramesh M, et al. [25] studied the failure mechanism and thermo-mechanical properties of fibre/filler reinforced polyester matrix composites and reported that filler-matrix debonding is the primary failure mechanism of composites above $360^{\circ} \mathrm{C}$. Saha et al. [4] studied dynamic mechanical investigations on chemically modified jute fibre and polyester 
composites and concluded that chemically treated fiber improves storage modulus and thermal transition temperature of the composites. Investigation of dynamic mechanical properties, dynamic modulus, and internal friction over a wide range of temperature is useful in studying the polyester composite structure. Talegaonkar and Gopinath [6] conducted the compressive strength of friction composites and concluded that compressive strength of composite increased with increase in alumina fiber content.

\subsection{Experimental Properties}

In this study, mechanical properties (hardness load, impact strength, bending distortion and thermal conductivity property behaviours of $\mathrm{SiC} /$ filled polyester composites and unfilled materials were examined. This study evaluates the influence of filling component $\mathrm{SiC}$ on thermo- mechanical behaviour of polyester composites and the effect of this material on the final applications of these composites.

\section{Materials and Methods}

Commercially available $\mathrm{SiC}$ powder known as carborundum of particle size 25 to $60 \mu \mathrm{m}$ (Density $2.6 \mathrm{~g} / \mathrm{cm} 3$ ), is used as particulate filler. Also the unsaturated polyester resin (Elastic modulus $3.25 \mathrm{Gap}$, density $1.35 \mathrm{gm} / \mathrm{cc}$ ) was used as base material. The composites were fabricated by blending unsaturated polyester resin, and $\mathrm{SiC}$ filler in a certain weight percentage reinforcement. Six different compositions of composites were prepared by varying the $\mathrm{SiC}$ filler, at different additive weight percentages $(0,3,6,10,13$, and $16 \mathrm{wt} . \%)$ in order to study the effect of $\mathrm{SiC}$ reinforcement on mechanical and thermal properties of SiC-reinforced polyester composites.

The proper proportions of the various ingredients were blended in a laboratory mixer. Initially the filler particles were added with further mixing for about $10 \mathrm{~min}$. Finally $2 \%$ methyl-ethyl-ketone- peroxide (MEKP) as a hardener is mixed in the resin prior to reinforcement unsaturated polyester resin based binder was added and final mixing was carried out for another $5 \mathrm{~min}$. After mixing operation, the polyester composites were fabricated by conventional hand lay-up technique to prepare Composites polyester of different compositions $(0,3,6,10,13$ and $16 \mathrm{wt}$. \% SiC filling) respectively. The mould was initially preheating up to $80^{\circ} \mathrm{C}$, then oiled with a thin layer of oil Vaseline (which acts as a barrier between the composite and the mould cavity). After preheating, the mould cavity was filled with composite mixture and then placed on the mould under load in order to maintain a secure bonding between friction composite and moulds. The assembly was subjected to drying under ambient atmospheric pressure at $37^{\circ} \mathrm{C}$ and $24 \mathrm{hrs}$ for proper curing; the curing cycle completion refers to the toughening of a composite. After curing, the composite moulds were removed from the mould. Then specimens were prepared as American Society for Testing Materials (ASTM) test standards to suitable dimensions by cutting them with a diamond cutter for different properties characterization according to ASTM standard. For, impact strength, hardness tests, bending distortion, and thermal conductivity. Tests for mechanical properties were determined to understand the behaviour of the material under different loading conditions to understand how materials deform or break as a function of applied load, time, temperature, and other conditions. 


\subsection{Hardness test}

The capability of the composite material to resist abrasion or indentation is known as hardness. A Rockwell hardness tester is used to measure the hardness of the composite specimen spherical indenter (1/16 in or $1.5875 \mathrm{~mm}$ diameter) was forced into the surface of the material under conditions of controlled magnitude and rate of loading. The size of indentation is the measure of amount of hardness of the specimen according to ASTM E$18[14]$.

\subsection{Impact test}

Impact test is done to notice the energy consuming capacity of the composite material before fracture. Charpy V-notch impact test samples with dimensions $64 \mathrm{~mm} \times 12.7 \mathrm{~mm} \times 3.2 \mathrm{~mm}$ were prepared with a V-notch groove $(2.5 \mathrm{~mm}$ depth) in the center of the specimen. The specimen was fixed on the impact tester such that the notch was at the opposite face to the striking end of the hammer Low velocity instrumented impact tests were carried out on composite specimens. The tests were done as ASTM D -256 using an impact tester. The pendulum impact testing machine as certain the notch impact strength of the material by shattering the $\mathrm{V}$ notched $\left(45^{\circ}\right)$ specimen with a pendulum hammer, measuring the spent energy, and relating it to the cross section of the specimen. The standard specimen for ASTM D- 256 is $60 \times 10 \times 4 \mathrm{~mm} 3$ and the depth under the notch is $2 \mathrm{~mm}$ [14]. The machine is adjusted such that the blade on the free-hanging pendulum just barely contracts the specimen (zero position). The specimens were clamped in a square support and were struck at their central point by a hemispherical bolt of diameter $5 \mathrm{~mm}$. The respective values of impact energy of different specimens were recorded directly from the dial indicator.

\subsection{Bending distortion}

A three-point bend test was performed with a span length of $30 \mathrm{~mm}$ in between the supports and a cross-head speed of $10 \mathrm{~mm} / \mathrm{min}$ to measure the amount of failure when subjected to loading. Rectangular test specimen with dimensions $157 \mathrm{~mm}$ length, $12.7 \mathrm{~mm}$ width, and $6.35 \mathrm{~mm}$ thickness has been used for the experiment according to ASTM D-256[14].

\subsection{Thermal conductivity}

The thermal conductivity test is achieved using Lee's disk instrument (Koeyigit Electronic, UK). The thermal conductivity is calculated by the following equations:

$$
\begin{aligned}
& \mathrm{e}=\mathrm{P} / \pi \mathrm{r}[\mathrm{r}(\mathrm{T} 1+\mathrm{T} 3)+2(\mathrm{~d} 1 \mathrm{~T} 1+0.5 \mathrm{ds}(\mathrm{T} 1+\mathrm{T} 2)+\mathrm{d} 2 \mathrm{~T} 2+\mathrm{d} 3 \mathrm{~T} 3] \\
& \mathrm{K}=\mathrm{e} \mathrm{ds}[\mathrm{T} 1+2 \mathrm{~T} 1(\mathrm{~d} 1+0.5 \mathrm{ds}) / \mathrm{r}+\mathrm{T} 2 \mathrm{ds} / \mathrm{r}] /(\mathrm{T} 2-\mathrm{T} 1)
\end{aligned}
$$

Where:

$\mathrm{e}=$ loss in heat per unit area in $\left(\mathrm{w} / \mathrm{cm} 2 . \mathrm{c}^{\circ}\right)$.

$\mathrm{P}=$ supplied power in $(\mathrm{w})$.

$\mathrm{r}=$ radius of disk in $(\mathrm{cm})$.

$\mathrm{d} 1, \mathrm{~d} 2, \mathrm{~d} 3=$ thickness of disks in $(\mathrm{cm})$.

$\mathrm{ds}=$ thickness of specimen in $(\mathrm{cm})$.

$\mathrm{T} 1, \mathrm{~T} 2, \mathrm{~T} 3=$ measured temperatures of disks no., 1,2 , and 3 in $\left(\mathrm{c}^{\circ}\right)$.

$\mathrm{K}=$ thermal conductivity in $\left(\mathrm{w} / \mathrm{cm} \cdot \mathrm{c}^{\circ}\right)$. 


\section{Results and Discussion}

\subsection{Effect of filler content on impact strength of the composites}

The impact property of a material is the capacity of the material to absorb and dissipate energy under impact or shock loading. Generally, the impact failure of a composite occurs by factors like matrix fracture, Figure1. It shows that the resistance to impact loading of the polyester composites improved with the addition of $\mathrm{SiC}$ fillers. For the composite without filler content the impact energy is $10 \mathrm{~J}$ and with the addition of SiC filler, from $3 \mathrm{wt} \%$ to 16 $\mathrm{wt} \%$, the impact energy increases from $17 \mathrm{~J}$ to $55 \mathrm{~J}$ respectively. Therefore, impact strength marginally increases in this study when the wt $\%$ of filler is increased from $3 \mathrm{wt} \%$ to $16 \mathrm{wt} \%$. The suitability of a composite for such applications should therefore be determined not only by the usual design parameters, but by its impact or energy absorbing properties. Then the addition of chemosphere, improves the impact strength of the composite. This may be due to the reason that chemosphere particles are rigid and have much higher fracture strength as compared to polyester resin. Additionally, the increase in chemosphere content increases the strength up to certain limit after which the impact strength is decreased on further addition. Based on the literature review, it has been found that the benefits of using $\mathrm{SiC}$ as reinforcement are improved stiffness, strength, and chemical stability (Kaundal et al. 2012) $[13,15,26,23]$.This indicates that property of polyester matrix changes from brittle to tough. Moreover, toughness increases the stiffness too. More amount of energy is absorbed by the material to overcome the resistance to crack propagation. Thus $\mathrm{SiC}$ a based Polyester composite have an ability to absorb more energy and has greater fracture strength as compared to unfilled composites and hence can prevent propagation.

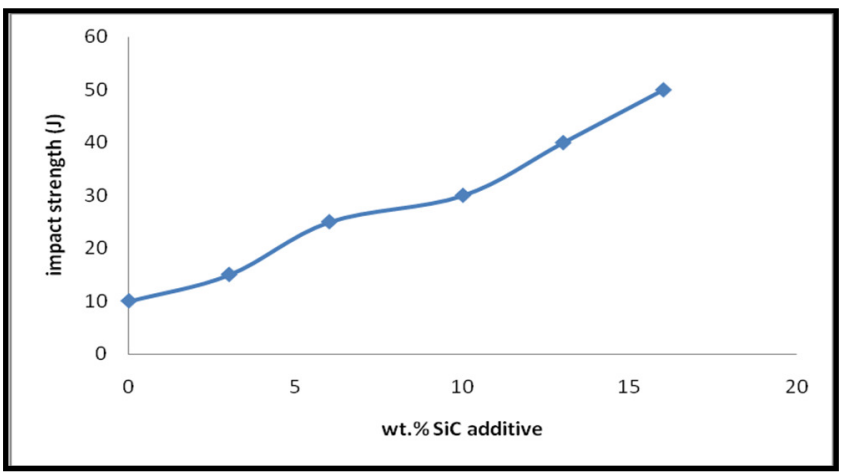

Fig. 1. estimates the Effect of filler content on impact strength of the composites.

\subsection{Effect of filler content on bending distortion of the composites}

The effect of different weight ratios of prepared samples in terms of bending distortion in $(\mathrm{mm})$ versus load in $(\mathrm{g})$ is shown in Figure (2). It indicates that the resistance to bending distortion is increased due to high weight ratio for all samples due to chemical compatibility between Matrix (PE) and reinforcement parts fillers particles SiC. The results indicate that the ultimate bending strength for the composite with silicon carbide of $16 \mathrm{wt}$. \% filler is higher than the other composite with silicon carbide filler additives ratio and without silicon carbide filler [8]. 


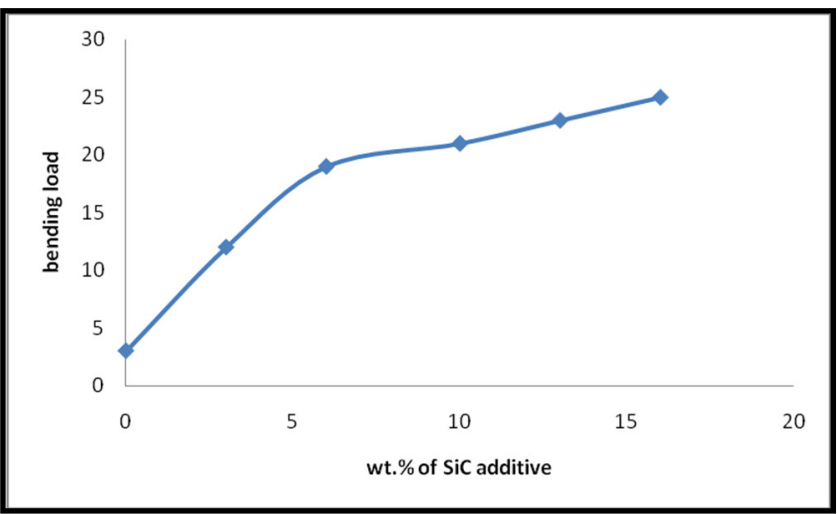

Fig. 2. estimate the Effect of filler content on bending distortion of the composites.

\subsection{Effect of filler content on Hardness strength of the composites}

The hardness property is describing the physical state of the system and is a measure of wear resistance on the surface of the composite as shown in Figure (3). It is observed from the results that the hardness values are improved with increasing in $\mathrm{SiC}$ contents in the polyester composite. The composite with $16 \mathrm{wt} \% \mathrm{SiC}$ content is found to exhibit an increase in hardness as compared to the unfilled composite. For unfilled polyester composite the hardness value is $64 \mathrm{~J}$ but with the addition of $3 \mathrm{wt} \%$ and $16 \mathrm{wt} \% \mathrm{SiC}$ filler contents in the composite this hardness value increases to $79 \mathrm{~J}-90 \mathrm{~J}$. In the case of the hardness test, a compression or pressing stress is in action, so the matrix phase and the solid filler phase would be pressed together and touch each other more significantly. Thus the interface can these results in enhanced transfer pressure more effectively although the interfacial bond may be poor hardness. The increase in adhesion between matrix polyester and reinforcement and reduced in the porosity due to addition of $\mathrm{SiC}$ content. Increase in filler content in the reinforced polymer composites decreases inter particle distance, which results in increased hardness $[21,22]$.

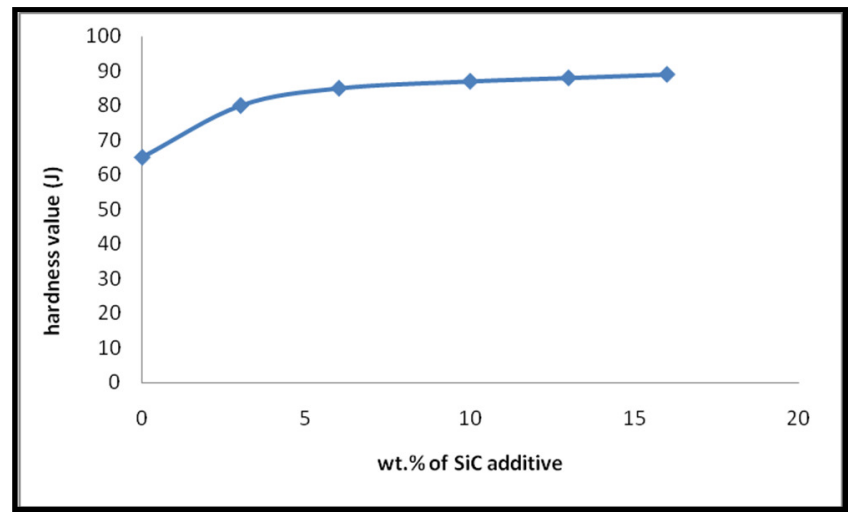

Fig. 3. estimate the Effect of filler content on Hardness strength of the composites. 


\subsection{Effect of filler content on thermal Conductivity of the composites}

The thermal conductivity, for different composition of composite materials are presented and their variations shown in Figure 4. Thermal conductivity is the property describing a material's ability to transfer heat. It is well known that thermal conductivity of the composite is dependent on such factors as Polymer-filler interaction and filler characteristics, namely type and shape of filler. From the obtained results it is observed that composites filled by (16\% wt.) SiC exhibited maximum thermal conductivity $\left(0.01 \mathrm{~W} / \mathrm{m}^{\circ} \mathrm{c}\right)$. From the literature review we can observed that $\mathrm{SiC}$ particles having good thermal conductivity property. Hematite filled composites also exhibited high thermal conductivities when compared base material because $\mathrm{SiC}$ filled composite exhibited less thermal expansion coefficient this may be by adding the more fillers in composite materials providing good filler matrix interaction in the system, the filler binds the matrix and prevents it from expanding as much as it would on its own. Subsequently, this would affect the thermal expansion of the composite system. The many studies have shown that materials with higher filler content leads to a lower thermal expansion coefficient. Particle having reduced thermal expansion and good dimensional stability [18, 20, 26].

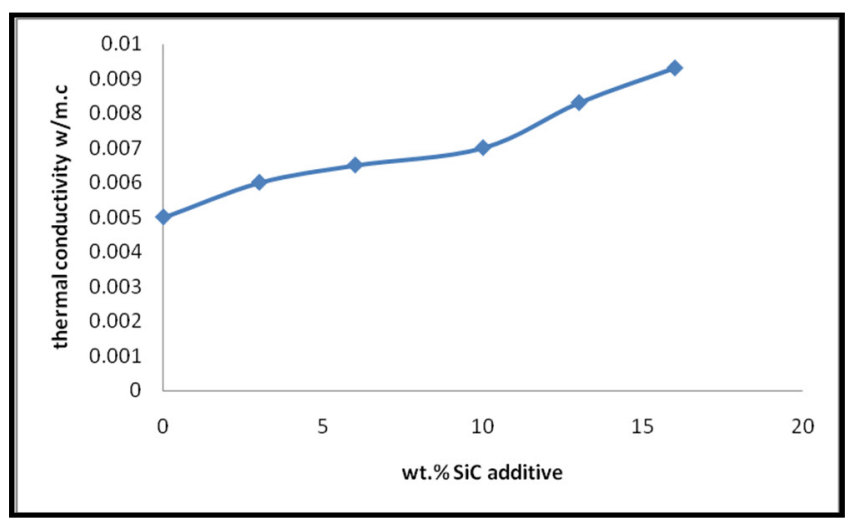

Fig. 4. estimate the Effect of filler content on thermal Conductivity of the composites.

\section{Conclusion}

Based on the present study on thermo-mechanical behaviour of $\mathrm{SiC}$ filled reinforced polyester composite the following observations and conclusions are made as:

1. The impact strength and hardness of the composites increases with increasing SiC filler contents in the polyester composites. This establishes that the addition of filler contents causes the erosion resistance of the composite to increase. The results reveal the sensitivity of the impact properties to the concentration of the fillers.

2. The value of hardness and impact strength increases up to $16 \mathrm{wt} . \%$ filler content; the value of bending distortion load increases up to $16 \mathrm{wt} \% \mathrm{SiC}$ filler content.

3. From the analysis of the results of mechanical properties and thermal properties, it has been concluded that the optimum properties are obtained for 16 wt. \% SiC.

4. When increase the adding of filler materials to composites reduces the thermal expansion coefficient it is. Composites filled by $\mathrm{SiC}$ exhibited low thermal expansion coefficient when compared with other unfilled composites. 


\section{References}

1. K Jung-Il, PH Kang and YC Nho. J. Appl. Polymer. Sci,; 92,394-401 (2004).

2. QH Wang, QJ Xue, WM Liu and JM Chen. Wear; 243, 140-146 (2000).

3. GL Harris. Properties of Silicon Carbide.IET. INSPEC. The Institution of Electrical Engineers, London, p.170-80 (IoffeInstitute, 2009).

4. A. K. Saha, S. Das, D. Bhatta, and B. C. Mitra, J. Appl. Polymer. Sci., 71 (9), pp. 15051513 (1999).

5. Y. Wu, M. Zeng, Q. Xu, S. Hou, H. Jin, and L. Fan, Tribol. Int., 54, pp. 51-57 (2012).

6. R. P. Talegaonkar and K. Gopinath, J. Reinf. Plast. Comp., 28 (17), pp. 2069-2081 (2009).

7. M. Rusu, N. Sofian, and D. Rusu, Polym. Test., 20 (4), pp. 409-417 (2001).

8. M. R. Willis and I. Masters, Compos. Struct., 62 (3), pp. 475-479 (2003).

9. A. Patnaik, A. Satapathy, S. S. Mahapatra, and R. R. Dash, J. Reinf. Plast. Comp., 27 (10), pp. 1039-1058 (2008).

10. Arijit Das, Bhabani K. Satapathy, Mater. Design, 32, pp. 1477-1484 (2011).

11. B. Suresha, G. Chandramohan, Siddaramaiah and T. Jayaraju, Polym. Composite., 29 (3), pp. 239-344 (2008).

12. M. Shibata, K. Takachiyo, K. Ozawa, R. Yosomiya and H. Takeishi, J. Appl. Polymer. Sci., 85 (1), pp. 129-138 (2002).

13. J. C. Lin, L. C Chang, M. N. Nien, and H. L Ho, Compos. Struct., 74 (1), pp. 30-36 (2006).

14. ASTM (American Society for Testing and Materials) Standard D 256-97: standard test methods for determining the pendulum impact resistance of notched specimens of plastic, Annual book of ASTM standards, 8 (1). (ASTM, West Conshohocken, pp 0120, 1997)

15. Kaundal R, Patnaik A, Satapathy A, Silicon, 4, pp. 175-188 (2012).

16. Sua F, Zhang Z, Wang K, Jiang W, Liu W, Compos. Part A, 36, 1601-1607 (2005).

17. Agarwal et al. Int. J. Adv. Structur. Eng., 16 (2013).

18. Maries Indicula, Abderrahim Boudenne. Compos. Sci. Technol., 66, pp. 2719-2725 (2006).

19. Dilek Kumlutas, Ismail H. Tavman. Compos. Sci. Technol., 63, pp. 113-117 (2003).

20. A. Shojaei, M. Fahimian. Compos. Sci. Technol., 67, pp. 2665-2674 (2007).

21. Antunes PV, Ramalho A, Carrilho EV P. Mater. Des., 61, pp. 50-60 (2014).

22. Fu S-Y, Feng X-Q, Lauke B, Mai Y-W, Composites Part B, 39, pp. 933-961 (2008).

23. Kaundal R, Patnaik A, Satapathy A. J Sci. Technol., 9, pp. 49-64 (2012).

24. Nafisa G, Shahzad MK, Muhammad AM, Muhammad S, Farheen A, Muhammad TZB, Tahir, J. Mater. Des. 67, pp. 313-317 (2015).

25. Ramesh M., PalaniKumar K., Hemachandra reddy. Compos: Part B, 48, pp. 1-9 (2013).

26. Falak O. Abas, Raghad O. Abas, Sarmad I. Ibrahim, Eng. Technol. J., 28 (12), pp.24692479 (2010). 